\title{
Microswitch beam-steering grid
}

\section{Jung-Chih Chiao}

Jung-Chih Chiao, "Microswitch beam-steering grid," Proc. SPIE 2250, International Conference on Millimeter and Submillimeter Waves and Applications 1994, 22507T (30 November 2017); doi: 10.1117/12.2303298

Event: Millimeter and Submillimeter Waves and Applications: International SPIE. Conference, 1994, San Diego, CA, United States 


\title{
Microswitch Beam-Steering Grid
}

\author{
Jung-Chih Chiao, David B. Rutledge \\ Department of Electrical Engineering, \\ California Institute of Technology, Pasadena, CA 91125
}

\begin{abstract}
We propose new microswitch beam-steering grids to operate at $90 \mathrm{GHz}$ and $240 \mathrm{GHz}$. The microswitch beam-steering grid has potential advantages over mechanical-scanning devices or active beam-steering reflectors based on diode grids such as lower loss and simple control circuits. Simulations predict that a 4-bit controlled 10-layer microswitch beam-steering grid can have phase-shift resolution of $22.5^{\circ}$ with a loss of $1.6 \mathrm{~dB}$ and a maximum phase error of $5^{\circ}$ at $240 \mathrm{GHz}$.
\end{abstract}

\section{INTRODUCTION}

Electrically scanned beam-steering systems allow a beam to shift rapidly, so that several targets can be tracked simultaneously. Previous work considered periodic structures loaded with diodes for millimeter-wave beam-steering systems. Chekroun et al. proposed Radant, a threedimensional grid of diodes for steering a beam [1]. Lam et al. demonstrated a phase shift of $70^{\circ}$ with a $7 \mathrm{~dB}$ loss at $93 \mathrm{GHz}$ on a $2 \mathrm{~cm}$ square GaAs diode grid with 1600 Schottky-barrier varactor diodes [2]. Recently, Sjogren et al. have demonstrated electronic beam-steering and focusing on a diode grid with 8640 diodes [3]. In these designs, it is extremely important to keep series resistance of diodes as low as possible to reduce losses.

Petersen developed micromechanical $\mathrm{SiO}_{2}$ membrane switches on silicon [4]. These switches are electrostatically controlled with metal-to-metal contacts (Fig. 1). The series resistance of the switch is very low, only $2 \Omega$. Switches were demonstrated with switching voltages between $20 \mathrm{~V}$ and $62 \mathrm{~V}$ and a switching time of $40 \mu \mathrm{s}$. We propose a novel beam-steering method which uses these microswitches instead of diodes [5]. Shown in Fig. 2 is one waveguide element in the grid. To change the phase of propagating wave, we utilize the two states of the microswitches. When the switches close, a shunt inductive reactance is presented to the incident wave, and when the switches open, a shunt capacitive reactance is presented to the propagating wave. The metal pattern in the waveguide provides the required reactance.

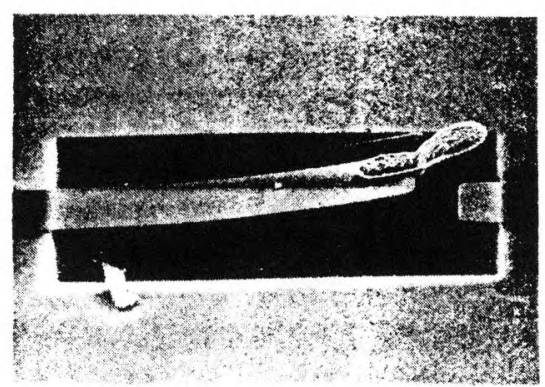

Figure 1: A micromechanical $\mathrm{SiO}_{2}$ membrane switch on silicon. It is about $100 \mu \mathrm{m}$ long. Work of Kurt Petersen at IBM [3] Proc. of SPIE Vol. 2250, 22507T · (c) (1994) 2017 SPIE · CCC code: 0277-786X/17/\$18 · doi: 10.1117/12.2303298 


\section{Approach}

We plan to fabricate microswitches on $\langle 110\rangle$ orientation silicon wafers in a periodic pattern. By using an anisotropic etchant $(\mathrm{KOH})$, rhombic waveguides with $\langle 111\rangle$ walls can be formed. Fig. 3 shows the structure. The whole structure will have 10 lapped layers in order to create a $2 \pi$ phase shift. Each column is controlled by parallel bias lines, which will provide the elements in the same column with the same phase shift. By changing the settings of switches in different layers, different phase shifts can be achieved. Design and simulations were done for ten lapped grid layers with ten microswitches and ten sections of rhombic waveguide. Circuit model and simulation results are shown in Fig. 4. The series resistance is assumed to be $2 \Omega$ at $240 \mathrm{GHz}$, the electrical length of each waveguide section is $102^{\circ}$, and the characteristic impedance of the rhombic waveguide is $587 \Omega$ by calculation. By switching the microswitches to change the reactance in different layers, 4-bit control should be possible to create a $360^{\circ}$ phase shift with a resolution of $22.5^{\circ}$. The maximum loss is $1.6 \mathrm{~dB}$, including conductive loss, reflection loss and skin-effect loss for different switch settings. The maximum phase error is $5^{\circ}$.
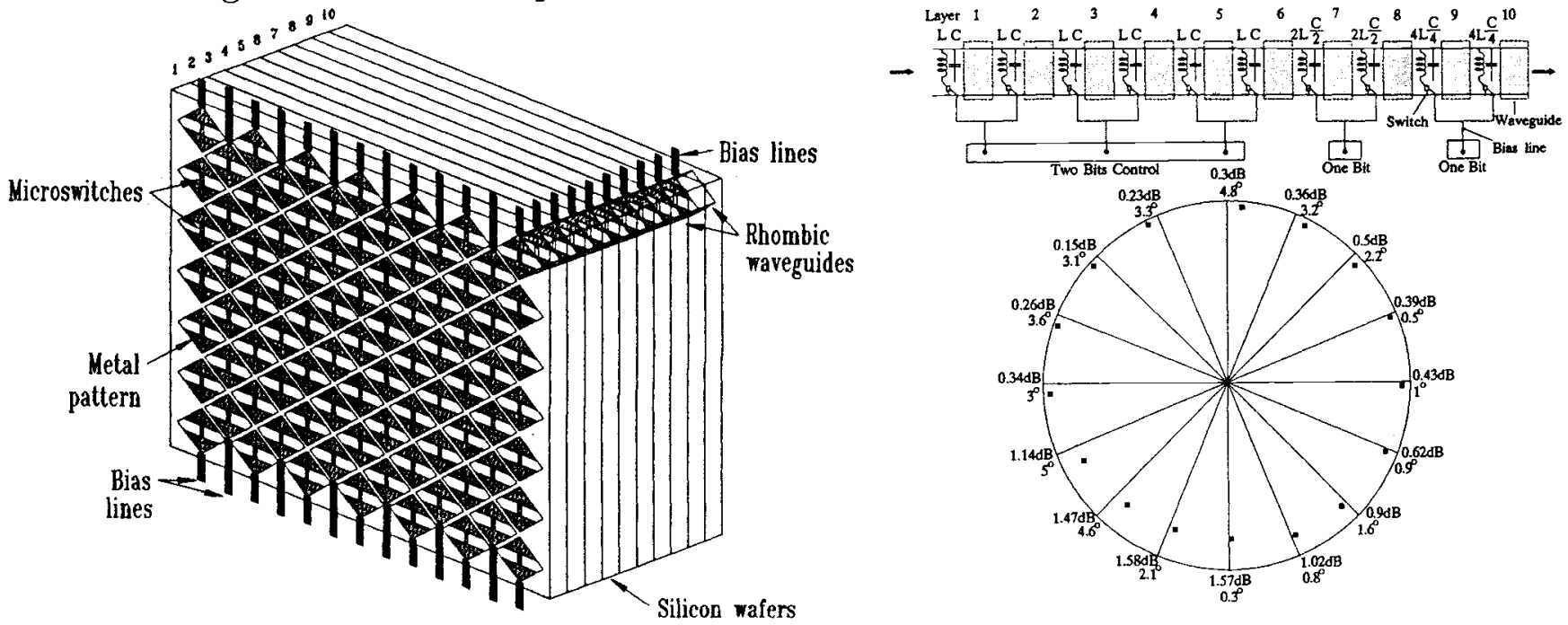

Figure 3: Design of the microswitch beam- Figure 4: Circuit simulation results: plot of steering grid with ten switch layers. magnitude and phase of transmission coefficients on a polar plot. The shunt elements are $\mathrm{L}=$ $514 \mathrm{pH}$ and $\mathrm{C}=0.86 \mathrm{fF}$.

\section{ACKNOWLEDGMENTS}

We appreciate the support of the Army Research Office and the Jet Propulsion Laboratory.

\section{REFERENCES}

[1] C. Chekroun, D. Herrick, Y. Michel, R. Pauchard, and P. Vidal, "Radant: New method of electronic scanning," Microwave J., pp.45-53, Feb. 1981.

[2] W. Lam, C. Jou, H. Chen, K. Stolt, N. Luhmann, Jr., and D. Rutledge, "Millimeter-wave diode-grid phase-shifters," IEEE Trans. on Microwave Theory and Techniques, pp.902-907, No. 5, May 1988.

[3] L.B. Sjogren, H.L. Liu, F. Wang, T. Liu, X.H. Qin, W. Wu, E. Chung, C.W. Domier, N.C. Luhmann, "A Monolithic Diode Array Millimeter-Wave Beam Transmittance Controller," to be published in IEEE Trans. on Microwave Theory and Techniques, Oct. 1993.

[4] K.E. Petersen, "Micromechanical Membrane Switches on Silicon," IBM J. Res. Develop., 23, pp. 376385 , No. 4, July 1979.

[5] J-C. Chiao, D.B. Rutledge "Microswitch Beam-Steering Grid," presented in the 17th International Conference on Infrared and Millimeter Waves, Dec. 1992. 